\title{
Evaluación de la actividad antifúngica de extractos liquénicos e identificación de sus metabolitos.
}

\author{
(Evaluation of the fungicide activity from lichens extracts and identification \\ their metabolites)
}

\author{
Daymara I Vaillant F', Carlos R Romeu C', \\ Marlene Gómez P2, Rebeca Ramírez 01. \\ 'Instituto de Investigaciones de Sanidad Vegetal (INISAV). \\ $110 \# 214 / 5^{\text {ta }}$ B y $5^{\text {ta }}$, Miramar, Playa. La Habana, Cuba \\ Código Postal 11600. Tel: 202-2517-19 ext 149. dvaillant@inisav.cu \\ 2Universidad Michoacana San Nicolás de Hidalgo. \\ Edificio R, Ciudad Universitaria. Francisco J. Mújica S/NCol. \\ Felicitas del Río. Código Postal 58030 Morelia, \\ Michoacán, México. Tel: 44331674 12. marlenegomezperalta@gmail.com \\ RECIBIDO: 25 de Agosto de 2014 \\ APROBADO: 06 de Octubre de 2014 \\ LOS AUTORES DECLARAN NO TENER CONFLICTO DE INTERESES
}

Palabras claves: Actividad fungicida, líquenes, sustancias liquénicas.

Key words: Fungicide activity, lichens, lichens substances.

\section{RESUMEN}

Los líquenes son los hongos que establecen una relación simbiótica con un alga o cianobacteria. En esta simbiosis se producen por parte del hongo, una serie de metabolitos secundarios conocidos como sustancias liquénicas; las cuales presentan una marcada actividad antibiótica. En Cuba no se tienen antecedentes sobre estudios de metabolitos liquénicos por lo que se propone; evaluar el efecto fungicida de extractos liquénicos producidos por especies cubanas así como identificar sus metabolitos. Se emplearon líquenes de diferentes zonas del país (Parmotrema dilatatum, P. tinctorum, P. praesorediosum P. cristiferum, Ramalina americana, Cladonia ceratophylla y Cladonia portentosa spp. pacífica), a los cuales se les extrajo con acetona, las sustancias liquénicas almacenadas en el talo. Los extractos fueron probados contra los hongos fitopatógenos Rhizoctonia solani y Phythophtora nicotianae; por el método de envenenamiento del medio de cultivo agar papa dextrosa a concentraciones de: $0,01 \% ; 0,03 \%$ y $0,07 \%$. Se utilizó un control negativo de dimetilsufóxido al $0,07 \%$ y se determinaron los porcentajes de inhibición, cuyos resultados fueron analizados estadísticamente. Los metabolitos secundarios presentes en los extractos se identificaron por cromatografía de capa fina (TLC). Exceptuando el extracto liquénico de $P$. cristiferum, todos los demás mostraron más de un $50 \%$ de inhibición del crecimiento de ambos hongos a la concentración de $0,07 \%$, mientras que a las restantes concentraciones los valores fueron variados con diferencias significativas con respecto al control. Se lograron identificar tres metabolitos liquénicos: metil 2'-0- metilmicrofilinato, 4-0-Demetilmicrofilinico y el ácido ramaniloico.

\section{ABSTRACT}

Lichens are fungi that establish a symbiotic relationship with an alga or cyanobacterium. This symbiosis produced by the fungus, a series of 
secondary metabolites known as lichen substances; which show a strong antibiotic activity. In Cuba there is no background on the studies above lichen metabolites so it is proposed; evaluate the fungicidal activity of lichen extracts produced by Cuban species and to identify metabolites. Lichens from different areas of the country (Parmotrema dilatatum, $P$. tinctorum, $P$. praesorediosum, $P$. cristiferum, Ramalina americana, Cladonia ceratophylla and Cladonia portentosa spp. pacifica), to which it extracted with acetone, the lichen substances stored in tallus. The extracts were tested against the fungal pathogens Rhizoctonia solani and Phythophtora nicotianae; poisoning by the method of culture medium potato dextrose agar at concentrations of $0.01 \% ; 0.03 \%$ and $0.07 \%$. A negative control to $0.07 \%$ dimethylsulfoxide was used and the percentage of inhibition, the results were analyzed statistically determined. Secondary metabolites present in the extracts were identified by thin layer chromatography $(\mathrm{TLC})$. Except $P$. cristiferum lichen extract, all others showed more than $50 \%$ growth inhibition of both fungi at concentration of $0.07 \%$, while the remaining concentrations were varied values with significant differences from the control. Was made to identify three lichen metabolites metilmicrofilinato 2 ' methyl-0, 4-0Demetilmicrofilinico and ramaniloico acid.

\section{INTRODUCCION}

Con el descubrimiento de las propiedades antibióticas de los metabolitos producidos por líquenes, muchos científicos comprobaron el efecto de estos sobre un número considerable de organismos patógenos, tanto para el hombre como para las plantas y animales. Desde la década de los años 40 diversos investigadores realizaron pruebas de actividad antibacteriana del ácido úsnico, sustancia producida fundamentalmente por especies del género Usnea (Ortega, 2004).

Los líquenes son excepcionales por la alta concentración de metabolitos que pueden almacenar en el talo, por lo que se pueden conservar por largos períodos de tiempo sin sufrir invasiones de bacterias y hongos, manifestándose así la actividad antimicrobiana de estas sustancias (Toledo et al., 2004). Estudios recientes demostraron que muchos de estos metabolitos tienen efecto sobre hongos fitopatógenos que afectan cultivos de gran importancia económica (Wei et al., 2008). Cuba presenta una gran diversidad de especies de líquenes; se informan un estimado de 800 especies de líquenes, y se teoriza que existan más (Minter et al., 2001). Sin embargo, no se tienen reportes de estudios sobre la actividad antibiótica de sustancias liquénicas, ni de identificación de sus metabolitos. Teniéndose en cuenta las afirmaciones anteriores, se propone: evaluar la actividad antifúngica de los extractos producidos por siete especies de líquenes, colectadas en diferentes zonas de Cuba sobre los hongos fitopatógenos $R$. solani Kün y Phytophthora nicotianae Breda de Haan; además de identificar sus principales metabolitos.

\section{MATERIALES Y METODOS}

\section{Colecta de líquenes}

Las colectas de los especímenes se realizaron en el año 2009 en tres regiones del país: La Habana, Cienfuegos y Holguín. Se seleccionaron líquenes con crecimiento cortícola y terrícola; además que se tuvo en cuenta la estimación cualitativa de la abundancia de la población liquénica para evitar depredar la zona. Las especies colectadas fueron identificadas mediante el uso de claves dicotómicas establecidas por: Brodo, 2001 y Nash et al. (2001; 2004; 2007). Los especímenes se muestran en la tabla 1.

\section{Prueba de la actividad fungicida de los extractos liquénicos}

Las muestras del talo liquénico de cada especímenes se lavaron con abundante agua corriente y se colocaron en la estufa a secar a $35^{\circ} \mathrm{C}$ durante 48 horas. Luego se trituraron hasta pulverizar y se pesaron $1 \mathrm{~g}$ de cada polvo. Esta porción se cubrió con $10 \mathrm{ml}$ de acetona y se dejó reposar durante 48 horas, hasta que el solvente extrajo la mayor cantidad de sustancias posibles; luego se filtró al vacío con papel de filtro y se desechó la biomasa. El sobrenadante se colocó en balones que fueron pesados vacios previamente y se concentró con un rotoevaporador rotatorio. Posteriormente por diferencia de los pesos de los balones; se determinó la cantidad de extracto obtenido y se disolvió en dimetilsulfoxido (DMSO) al 10\% para lograr los extractos al $5 \%$. Para los ensayos de antibiosis se prepararon concentra- 
Evaluación de la actividad antifúngica de extractos liquénicos - D. Vaillant et al

Tabla1. Especies de líquenes colectadas.

\begin{tabular}{|l|l|l|l|l|}
\hline \multicolumn{1}{|c|}{ Especies } & \multicolumn{1}{|c|}{ Localidad } & Fecha & Hábitat & Tipo de crecimiento \\
\hline Parmotrema dilatatum (Vain.) Hale & $\begin{array}{l}\text { Jardín Botánico } \\
\text { Cienfuegos }\end{array}$ & $26 / 02 / 09$ & Cortícola & Foliáceo \\
\hline $\begin{array}{l}\text { Parmotrema tinctorum (Despr. ex } \\
\text { Nyl.) Hale }\end{array}$ & $\begin{array}{l}\text { Jardín Botánico } \\
\text { Cienfuegos }\end{array}$ & $26 / 02 / 09$ & Cortícola & Foliáceo \\
\hline $\begin{array}{l}\text { Parmotrema praesorediosum } \\
\text { (Nyl.) Hale }\end{array}$ & $\begin{array}{l}\text { Jardín Botánico } \\
\text { Nacional } \\
\text { Habana) }\end{array}$ & $8 / 03 / 09$ & Cortícola & Foliáceo \\
\hline $\begin{array}{l}\text { Parmotrema cristiferum (Taylor) } \\
\text { Hale }\end{array}$ & $\begin{array}{l}\text { Jardín Botánico } \\
\text { Nacional } \\
\text { habana) }\end{array}$ & $8 / 03 / 09$ & Cortícola & Foliáceo \\
\hline $\begin{array}{l}\text { Ramalina americana Hale } \\
\text { Cayo Mujeres } \\
\text { (Holguín) }\end{array}$ & $\begin{array}{l}\text { Cayo Mujeres } \\
\text { (Holguín) }\end{array}$ & $18 / 03 / 09$ & Terrícola & Fruticoso \\
\hline $\begin{array}{l}\text { Cladonia ceratophylla (Sw.) } \\
\text { Spreng. }\end{array}$ & $\begin{array}{l}\text { Pinares de Mayarín } \\
\text { (Holguín) }\end{array}$ & $22 / 03 / 09$ & Terrícola & Fruticoso \\
\hline $\begin{array}{l}\text { Cladonia portentosa ssp.pacificola } \\
\text { (Ahti) Ahti }\end{array}$ & & Fruticoso \\
\hline
\end{tabular}

ciones de $0,07 \%, 0,03 \%$ y $0,01 \%$ de cada extracto en PDA fundido (Tabla 2).

Tabla 2. Preparación de las concentraciones.

\begin{tabular}{|l|l|l|}
\hline Concentración & $\begin{array}{c}\text { Cantidad de } \\
\text { extracto }\end{array}$ & $\begin{array}{c}\text { Cantidad de PDA } \\
\text { fundido para } \mathbf{5 0} \mathbf{~ m l}\end{array}$ \\
\hline $0,07 \%$ & $0,07 \mathrm{ml}$ & $49,3 \mathrm{ml}$ \\
\hline $0,03 \%$ & $0,03 \mathrm{ml}$ & $49,7 \mathrm{ml}$ \\
\hline $0,01 \%$ & $0,01 \mathrm{ml}$ & $49,9 \mathrm{ml}$ \\
\hline
\end{tabular}

El PDA fundido suplementado con cada uno de los extractos liquénicos, se aplicó en placas de $5 \mathrm{~cm}$ de diámetro y se colocaron en el centro ponchetes de $1 \mathrm{~cm}$ de diámetro de los hongos fitopatógenos Phytophthora nicotianae y Rhizoctonia solani aislados de cultivo de papa (Solanum tuberosum L). En el ensayo se emplearon dos controles; uno con el blanco
DMSO al $5 \%$ que se aplicó al medio de cultivo a la mayor concentración estudiada. Las placas se incubaron a $25^{\circ} \mathrm{C}$ durante 7 días y pasado este tiempo se midieron los diámetros de las colonias tratadas y las testigos para calcular el porcentaje de inhibición empleando la siguiente fórmula:

\section{$\%$ inhibición $=(D C C-D C T) /$ DCC $\times 100$}

Donde:

DCC: diámetro de la colonia control

DCT: diámetro de la colonia tratada

Los datos de los experimentos se procesaron mediante análisis de varianza de clasificación simple (ANOVA) utilizando el programa Analest. Las medias se docimaron utilizando la Prueba de Tukey $(p<$ 0.05).

\section{Determinación de la dosis inhibitoria media (DI50)}

Se determinaron además las dosis inhibitorias 
Evaluación de la actividad antifúngica de extractos liquénicos - D. Vaillant et al

medias de los porcentajes de inhibición de cada uno de los extractos liquénicos utilizando el programa ED50plus v1.0 (Vargas, 2000).

\section{Identificación de las sustancias liquénicas}

La identificación de los metabolitos liquénicos se realizó por cromatografía de capa fina (TLC), siguiendo la metodología descrita por Gómez, 1997. Se emplearon cuatro placas de silicagel (60 F254) de $0,2 \mathrm{~mm}$ de grosor y de $20 \times 20 \mathrm{~cm}$ de tamaño; las cuales fueron tratadas en cuatro fases móviles (FM), teniéndose en cuenta los valores de índice de retención (Rf) de las sustancias liquénicas para cada sistema de solvente mencionado en el programa wintabolites.

Las FM fueron las siguientes:

FM- A: touleno/dioxano/ácido acético: (36:9:1, $46 \mathrm{ml})$.

FM-B: hexano/dietiléter/ ácido fórmico (26: 16:4, $46 \mathrm{ml}$ ).

FM-C: tolueno/ácido acético (40:6, $46 \mathrm{ml})$.

FM-E: Hexano/ acetato de etilo (30: 16, $46 \mathrm{ml})$.

Una vez concluida la cromatografía, se calcularon los respectivos índices de retención de las sustancias liquénicas que se detectaron en las placas mediante la siguiente fórmula:

$\mathbf{R f}=\frac{\mathrm{a}}{\mathrm{b}} \times 100$

a: Distancia que recorrió cada sustancia midiendo del punto de aplicación hasta el centro de la mancha.

b: Distancia que recorrió el solvente, midiendo a partir del punto de aplicación.

Para la identificación de los metabolitos presentes en cada uno de los extractos se utilizó el programa wintabolites (1994).

\section{RESULTADOS}

\section{Prueba de la actividad fungicida de los extractos liquénicos}

Los datos de la actividad fungicida de los extractos liquénicos fueron tabulados para cada hongo. La tabla 3 muestra los porcentajes de inhibición de cada uno de los extractos para $P$. nicotianae.

Tabla 3. Porcentajes de inhibición de cada extractos para $P$. nicotianae.

\begin{tabular}{|l|c|c|c|}
\hline Extractos liquénicos & $\begin{array}{c}\text { \% de inh al } \\
\mathbf{0 , 0 7 \%}\end{array}$ & \% de inh al $\mathbf{0 , 0 3} \%$ & \% de inh al $\mathbf{0 , 0 1 \%}$ \\
\hline & & & \\
\hline Parmotrema dilatatum & $73,3 \mathrm{e}$ & $72,6 \mathrm{e}$ & $56,1 \mathrm{~g}$ \\
\hline Parmotrema tinctorum & $59,5 \mathrm{c}$ & $53 \mathrm{c}$ & $45 \mathrm{f}$ \\
\hline Parmotrema praesorediosum & $100 \mathrm{~g}$ & $63,1 \mathrm{~d}$ & $38,5 \mathrm{e}$ \\
\hline Parmotrema cristiferum & $43,1 \mathrm{~b}$ & $40 \mathrm{~b}$ & $33,9 \mathrm{c}$ \\
\hline Ramalina americana & $68,9 \mathrm{de}$ & $31,1 \mathrm{~b}$ & $15,6 \mathrm{~b}$ \\
\hline Cladonia ceratophylla & $80,9 \mathrm{f}$ & $65,11 \mathrm{~d}$ & $22,2 \mathrm{c}$ \\
\hline Cladonia portentosa spp. pacífica & $64,4 \mathrm{~cd}$ & $60 \mathrm{~cd}$ & $31 \mathrm{~d}$ \\
\hline Control (con DMS0) & $0 \mathrm{a}$ & $0 \mathrm{a}$ & $0 \mathrm{a}$ \\
\hline Control (sin DMS0) & $0 \mathrm{a}$ & $0 \mathrm{a}$ & $0 \mathrm{a}$ \\
\hline
\end{tabular}


El extracto obtenido de $P$. praesorediosum al $0,07 \%$ logró inhibir en un $100 \%$ el crecimiento de $P$. nicotianae. Por otra parte; P. dilatatum, P. tinctorum, $R$. americana, C. ceratophylla y C. portentosa mostraron más de un $50 \%$ de inhibición a esta misma concentración (fig 1). Los metabolitos producidos por $P$. cristiferum fueron los de más baja actividad. $R$. americana no tuvo diferencias significativas con $P$. dilatatum y $C$. portentosa y esta última a su vez, no mostró diferencias significativas con $P$. tinctorum. Todos los extractos mostraron diferencias significativas con respecto al control negativo.

Los resultados alcanzados al $0,03 \%$, exceptuando los de $R$. americana y $P$. cristiferum, estuvieron por encima del $50 \%$ de inhibición; sin diferencias significativas entre las especies Parmotrema praesorediosum, Cladonia ceratophylla y Cladonia portentosa. Otros productos que no mostraron diferencias significativas entre sí fueron los obtenidos de $C$. portentosa y $P$. tinctorum.

A la menor concentración solo los extractos producidos por $P$. dilatatum y $P$. americana inhibieron más de un $50 \%$ el crecimiento micelial de P. nicotianae, los restantes extractos estuvieron por debajo del $50 \%$, pero con diferencias significativas con respecto al control. Los metabolitos producidos por P. cristiferum y C. ceratophylla no tuvieron diferencias significativas entre sí. De manera general los extractos liquénicos obtenidos de $P$. americana y $P$. praesorediosum fueron los que mostraron mejor actividad fungicida frente $P$. nicotianae.

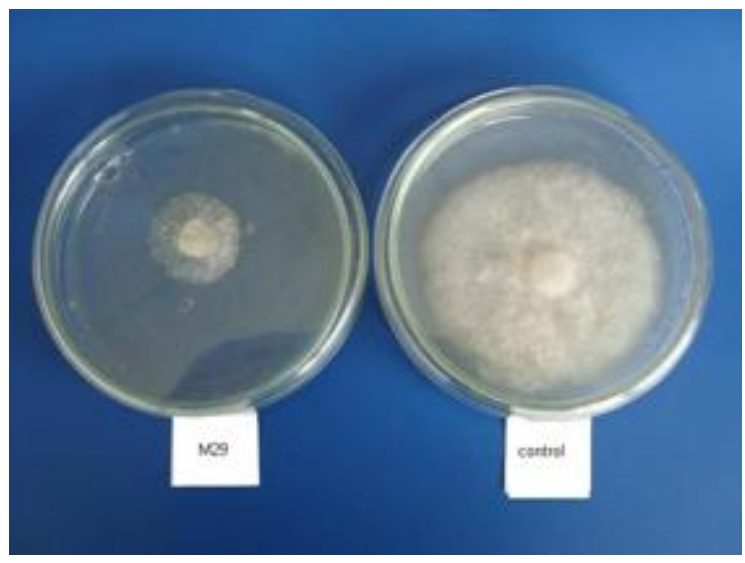

Figura 1. Efecto inhibitorio de las sustancias liquénicas producidas por Parmotrema tinctorum al 0,07\%
La tabla 4 por su parte muestra los porcentajes de inhibición para $R$. solani.

En general los extractos liquénicos mostraron menor actividad fungicida frente a $R$. solani que frente a $P$. nicotiane. Sin embargo al $0,07 \%$ los resultados fueron similares; $P$. dilatatum, $P$. praesorediosum, $R$. americana y $C$. portentosa mostraron valores de inhibición de más de un $50 \%$ (fig 2). El extracto de $P$. tinctorum no mostró ninguna actividad sobre $R$. solani; los restantes extractos a pesar que tuvieron valores por debajo del $50 \%$ mostraron diferencias significativas con el control negativo.

Al $0,03 \%$ solo los metabolitos producidos por P. dilatatum lograron valores de inhibición por encima del 50\%; mientras que los obtenidos de $P$. praesorediosum, P. cristiferum, C. ceratophylla y $C$. portentosa tuvieron baja actividad fungicida con diferencias significativas con respecto al control. En el caso específico de los extractos de $C$. ceratophylla y C. portentosa estos no presentaron diferencias significativas entre sí. Llama la atención la actividad inhibitoria del extracto de $R$. americana quien a la mayor concentración mostró un valor satisfactorio a las restantes concentraciones no mostró ninguna actividad.

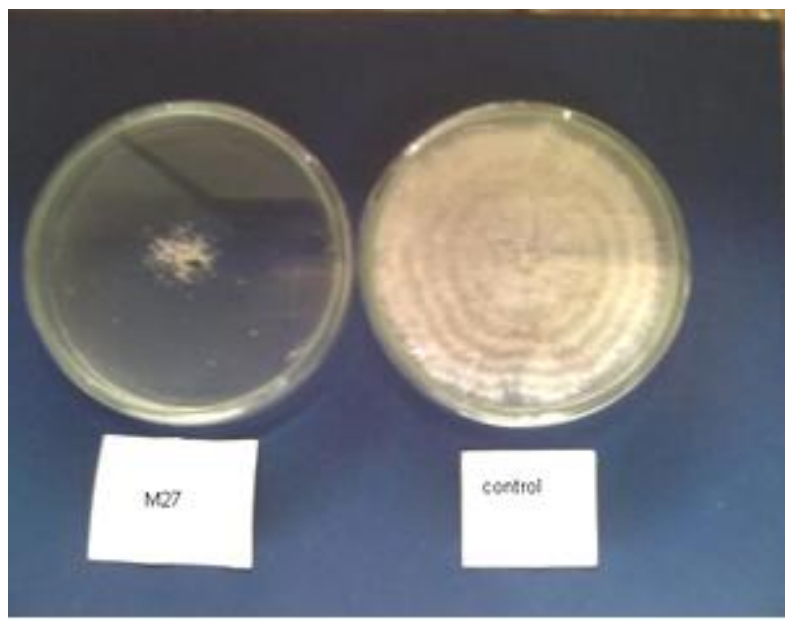

Fig. 2. Efecto inhibitorio de las sustancias liquénicas producidas por Parmotrema dilatatum al 0,07\%.

En la menor concentración solo los extractos obtenidos de las especies Parmotrema dilatatum y Parmotrema praesorediosum lograron inhibir el 
Evaluación de la actividad antifúngica de extractos liquénicos - D. Vaillant et al

Tabla 4. Porcentaje de inhibición de cada uno de los extractos sobre $R$. solani.

\begin{tabular}{|l|c|c|c|}
\hline \multicolumn{1}{|c|}{ Extractos liquénicos } & $\begin{array}{c}\text { \% de inh al } \\
\mathbf{0 , 0 7 \%}\end{array}$ & \% de inh al $\mathbf{0 , 0 3} \%$ & \% de inh al $\mathbf{0 , 0 1 \%}$ \\
\hline & & & \\
\hline Parmotrema dilatatum & $81,8 \mathrm{~g}$ & $70,7 \mathrm{e}$ & $42,2 \mathrm{~d}$ \\
\hline Parmotrema tinctorum & $0 \mathrm{a}$ & $0 \mathrm{a}$ & $0 \mathrm{a}$ \\
\hline Parmotrema praesorediosum & $54,4 \mathrm{~d}$ & $40,7 \mathrm{~d}$ & $22 \mathrm{c}$ \\
\hline Parmotrema cristiferum & $28,1 \mathrm{~b}$ & $26,7 \mathrm{~b}$ & $0 \mathrm{a}$ \\
\hline Ramalina americana & $78,7 \mathrm{f}$ & $0 \mathrm{a}$ & $0 \mathrm{a}$ \\
\hline Cladonia ceratophylla & $42,2 \mathrm{c}$ & $31,1 \mathrm{bc}$ & $0 \mathrm{a}$ \\
\hline Cladonia portentosa spp. pacífica & $64,4 \mathrm{e}$ & $33 \mathrm{c}$ & $0 \mathrm{a}$ \\
\hline Control (con DMS0) & $0 \mathrm{a}$ & $0 \mathrm{a}$ & $0 \mathrm{a}$ \\
\hline Control (sin DMS0) & $0 \mathrm{a}$ & $0 \mathrm{a}$ & $0 \mathrm{a}$ \\
\hline
\end{tabular}

Tabla 5. $\mathrm{DI}_{50}$ de los extractos liquénicos para cada hongo.

\begin{tabular}{l|c|c}
\multicolumn{1}{c|}{ Especies } & $\boldsymbol{P}$. nicotianae & $\boldsymbol{R}$. solani \\
\hline Parmotrema dilatatum & $0,012 \pm 0,003$ & $0,0137 \pm 0,0003$ \\
\hline Parmotrema tinctorum & $0,012 \pm 0,003$ & Dosis $>0,07 \%$ \\
\hline Parmotrema praesorediosum & $0,0176 \pm 0,0022$ & $0,041 \pm 0,007$ \\
\hline Parmotrema cristiferum & Dosis $>0,07 \%$ & Dosis $>0,07 \%$ \\
\hline Ramalina americana & $0,024 \pm 0,002$ & $0,0423 \pm 0,0045$ \\
\hline Cladonia ceratophylla & $0,0226 \pm 0,0006$ & Dosis $>0,07 \%$ \\
\hline $\begin{array}{l}\text { Cladonia portentosa spp. } \\
\text { pacifica }\end{array}$ & $0,013 \pm 0,003$ & $0,041 \pm 0,006$ \\
& &
\end{tabular}

Tabla 6. Sustancias liquénicas identificadas en los extractos por TLC (página siguiente). 
Evaluación de la actividad antifúngica de extractos liquénicos - D. Vaillant et al

\begin{tabular}{|c|c|c|c|}
\hline Especies de líquenes & Sustancias liquénicas & Clase & Sustancias relacionadas \\
\hline Parmotrema dilatatum & $\begin{array}{l}\text { Metil } 2 '-0- \\
\text { metilmicrofilinato }\end{array}$ & Dépsidos & Ácido 2'-0-metilmicrofilinico \\
\hline \multirow[t]{2}{*}{ Parmotrema tinctorum } & $\begin{array}{l}\text { Acido } \\
\text { dimetilmicrofilinico }\end{array}$ & Dépsidos & $\begin{array}{l}\text { Ácido anziaico, ácido } \\
\text { microfilinico, ácido olivetorico }\end{array}$ \\
\hline & $\begin{array}{l}\text { Metil } 2{ }^{\prime}-0- \\
\text { metilmicrofilinato }\end{array}$ & Dépsidos & Acido 2'-0-metilmicrofilinico \\
\hline \multirow[t]{2}{*}{$\begin{array}{l}\text { Parmotrema } \\
\text { praesorediosum }\end{array}$} & $\begin{array}{l}\text { Acido 4-0- } \\
\text { dimetilmicrofilinico }\end{array}$ & Dépsidos & $\begin{array}{l}\text { Ácido Anziaico, ácido } \\
\text { microfilinico, } \\
\text { olivetorico }\end{array}$ \\
\hline & $\begin{array}{l}\text { Metil } \\
\text { metilmicrofilinato }\end{array}$ & Dépsidos & Ácido 2'-0-metilmicrofilinico \\
\hline $\begin{array}{l}\text { Parmotrema } \\
\text { cristiferum }\end{array}$ & $\begin{array}{l}\text { Metil } \\
\text { metilmicrofilinato }\end{array}$ & Dépsidos & Ácido 2'-0-metilmicrofilinico \\
\hline \multirow[t]{2}{*}{ Ramalina americana } & Ácido Ramalinolico & Dépsidos & $\begin{array}{l}\text { Ácido 4'-0-dimetilsekikaico, ácido 4'-0- } \\
\text { Metilnorhomosekikaico, } \\
\text { Ácido 4'-0-Metilnorsekikaico, } \\
\text { Ácido Homosekikaico, ácido } \\
\text { Sekikaico }\end{array}$ \\
\hline & $\begin{array}{l}\text { Metil } 2 '-0- \\
\text { metilmicrofilinato }\end{array}$ & Dépsidos & Ácido 2'-0-metilmicrofilinico \\
\hline Cladonia ceratophylla & No se pudo determinar & & 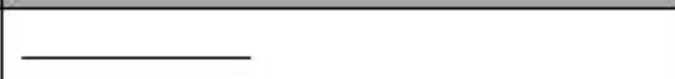 \\
\hline \multirow{2}{*}{$\begin{array}{l}\text { Cladonia portentosa } \\
\text { spp.Pacifica }\end{array}$} & No se pudo determinar & & $\ldots$ \\
\hline & $\begin{array}{l}\text { Metil } \\
\text { metilmicrofilinato }\end{array}$ & Dépsidos & Ácido 2'-0-metilmicrofilinico \\
\hline
\end{tabular}


crecimiento de $R$. solani con valores por debajo de la media, pero con diferencias significativas respecto al control. El resto de los extractos no tuvieron ningún efecto antifúngico.

\section{Determinación de la dosis inhibitoria media (DI50)}

Las dosis inhibitorias medias de los productos estudiados fueron determinadas y estuvieron en un rango de 0,012 a 0,042\% (tabla 5).

La dosis inhibitoria media es aquella dosis de un determinado producto que es capaz de inhibir la mitad del crecimiento de la colonia un período dado. $\mathrm{La} \mathrm{DI}_{50}$ más eficaz para $P$. nicotiane fue la obtenida de $P$. dilatatum y $P$. tinctorum y para $R$. solani resultó la de $P$. dilatatum con igual valor al de $P$. nicotianae.

\section{Identificación de las sustancias liquénicas}

Las sustancias liquénicas identificadas en cada uno de los extractos se muestran en la tabla 6.

De las sustancias reveladas por TLC hubo un compuesto que, exceptuando $C$. ceratophylla, fue común para todas las especies; dicho metabolito fue el metil 2 '-0- metilmicrofilinato perteneciente a las clase de los dépsidos (figura 3). Está compuesto fue positiva a la luz ultravioleta y tomó una coloración naranja cuando se aplicó ácido sulfúrico y fue detectada en las cuatro fases móviles empleadas en la cromatografía.

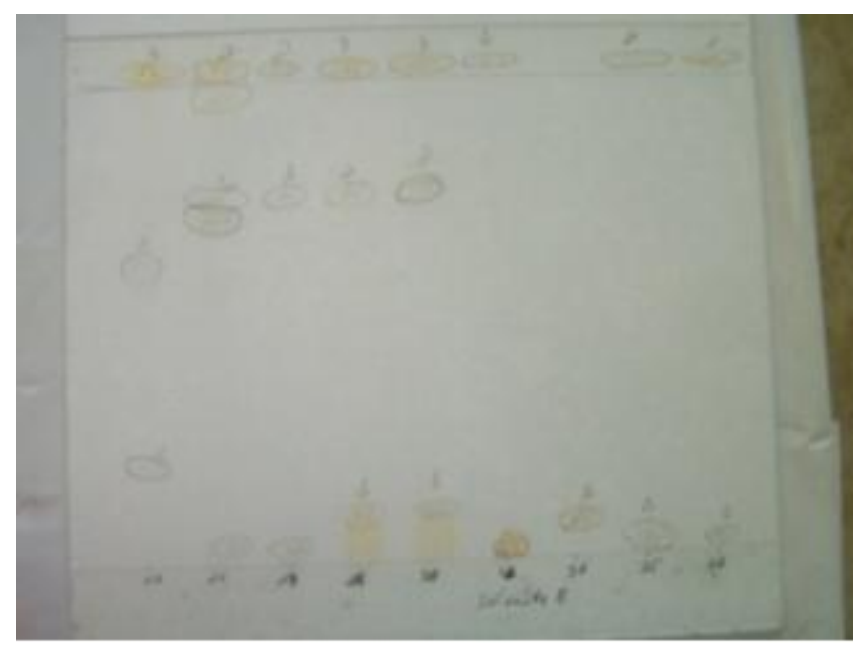

Figura 3. Resultado de TLC con solvente E.
Los líquenes $P$. tinctorum y $P$. praesorediosum mostraron los mismos compuestos liquénicos; el ácido 4-0-Demetilmicrofilinico un dépsido que presenta una coloración amarilla intensa cuando se aplica el ácido sulfúrico y cuya mancha fue detectada a la luz UV. En $R$. americana se identificó el ácido ramaniloico, sustancia perteneciente a la clase de los dépsidos que reacciona con ácido sulfúrico tomando una coloración entre amarillo o naranja claro. Esta sustancia se relaciona con otros compuestos liquénicos como el ácido sekikaiko. Las especies $C$. ceratophylla y $C$. portentosa revelaron una sustancia la cual no su pudo identificar por TLC. Este compuesto da una coloración carmelita pálido con ácido sulfúrico y es positivo con luz ultravioleta.

\section{DISCUSIÓN}

La actividad fungicida de metabolitos liquénicos fue reportada por investigadores como: Gullece et al. (2006) y Halama y Haluwin (2004) (citado por: Wei et al., 2008). También otros estudios con extractos liquénicos, como los efectuado por Suberu (2004), demostraron la capacidad de inhibir el crecimiento y la esporulación de Aspergillus flavus de los extractos de Hypogymnia physodes y Ramalina farinacea a concentraciones mayores a las utilizadas en este ensayo. Seoun et al. (2003) (citado por: Toledo et al., 2004) obtuvieron sustancias liquénicas de Heterodermia sp con una metodología similar a la empleada en este trabajo, mostrando valores significativos en un número determinado de hongos fitopatógenos entre los que se destacan Bipolaris coicis, Colletotricum orbiculare y Fusarium graminearum. Shai et al. (2001) utilizaron el extracto acuoso de Heterodermia leucomela obteniendo efecto de un $100 \%$ de inhibición a dosis de 60 y $80 \mu \mathrm{ml}^{-1}$ sobre los hongos fitopatógenos Cladosporium cladosporioides, Curvularia Iunata, Fusarium oxysporum y sobre especies del género Trichophyton. Por otra parte la especie Lecanora argentata obtuvo un $68 \%$ de inhibición de Colletotricum acutatum agente causal de la antracnosis del pepino, similar resultado mostró Cetrelia japonica (61,4\%), Ramalina conduplicans (59,5\%) y Umbilicaria esculenta (59,5\%), (Wei et al., 2008), todo esto ha dosis mayores a las de este estudio. 
Otros géneros que muestran un significativo efecto antifúngico son: Cladonia, Myelochroa, Parmelia y Usnea. El género Ramalina también presenta una marcada actividad fungicida, al igual que el género Parmelia cuyas especies inhibieron completamente el crecimiento de los hongos Botrytis cinerea, Rhizoctonia solani, Pythium sp y Sclerotium cepivorum (Soon et al., 2006).

Los extractos obtenidos de las especies de Parmotrema en este estudio mostraron valores de inhibición significativos principalmente contra $P$. nicotiane. Algunos autores como Teixeira et al. (2002) demostraron la actividad fungicida de algunas especies de este género, tal es el caso de $P$. tinctorum quien mostró efecto inhibitorio del crecimiento de Cladosporium sphaerospermum debido fundamentalmente a la presencia en el talo del ácido lecanórico (citado por: Wei et al., 2008). También P. praesorediosum inhibió el crecimiento de bacterias y levaduras patógenas en humanos, destacándose frente a Candida albicans (Balaji y Hariharan, 2007). Otras especies con efecto fungicida frente a hongos fitopatógenos son: Parmelia saxatilis y Parmelia sulcata las cuales revelaron además actividad inhibitoria en bacterias y hongos de importancia cliníca a concentraciones mínimas inhibitorias en un rango de 1,56-12,5 mg/ml (Rankovic y Kosanic, 2012).

Estudios recientes demuestran que el tipo de solvente empleado para la extracción de las sustancias liquénicas influye en la actividad antimicrobiana que pude presentar el extracto. Tiwari et al. (2011) estudiaron el efecto fungicida de los metabolitos producidos por las especies: Bulbothirx setschwanensis, Erverniastrum nepalense, Heterodermia diademata y Parmelaria thomsonii utilizando tres solventes diferentes (acetona, metanol y cloroformo), obteniéndose mejores resultados en los extractos con acetona frente a: Aspergillus flavus, A. fumigatus, Alternaria alternata, Fusarium oxysporum, F. solani, F. roseum y Penicillium citrinum.

De la literatura consultada no encontramos referencias sobre las dosis inhibitorias medias de los extractos liquénicos de estas especies. Existen otros estudios como los realizados por Prashith et al. (2012); donde emplearon extractos de Everniastrum cirrhatum contra Candida albicans y Cryptococcus neoformans con $\mathrm{DI}_{50}$ de $0,0474 \%$.

Los metabolitos identificados en este estudio pertenecen a la clase de los dépsidos y las depsidonas; estas clases de metabolitos conjunto con los ácidos úsnicos son compuestos que solo se encuentran en los hongos liquenizados (Rankovié et al., 2009). Estas sustancias son muy abundante en los talos liquénicos y pueden representar de un 5 a un $10 \%$ del peso seco del talo y mostrar actividad antioxidante, antiviral, antibiótica y antitumoral (Gulluce et al., 2006). Thadhani et al. (2012) aislaron de cuatro especies de líquenes; siete sustancias liquénicas pertenecientes a las clase de los dépsidos y las depsidonas. Entre las especies estudiadas se encontraban dos del género Cladonia. Estas sustancias fueron probadas frente a bacterias y hongos de importancia clínica y fitopatológicas, obteniéndose resultados significativos. Se destaca la relevante actividad antibacterial frente a bacterias Gram negativas y Gram positivas del ácido sekikaico; meta dépsido relacionado con el ácido ramaniloico identificado en la especie $R$. americana. Por otra parte los dépsidos probados por estos autores mostraron una marcada actividad fungicida en hongos fitopatógenos como Aspergillus flavus y Fusarium solani. El ácido lobárico inhibió en un 90\% el crecimiento micelial de $A$. flavus mientras que el metil$b$-orcinolcarboxilato mostró igual resultado para $F$. solani.

Nash et al. (2001) reportan la presencia de antranorina en las tres especies del género Parmotrema analizadas; sin embargo en este trabajo no se identificó esta clase de sustancia. También en P. praessorediosum; estos mismos autores reportan metabolitos como la cloroantranorina en el corteza y en la médula Ios ácidos praesorediosico y protopraesorediosico. En estudios realizados por Kusumaningrum et al. (2011) en extracto acetónico de $P$. tinctorum; identificaron solamente depsidona y dépsidos. Barrero y PerézOrtega (2003), describen que en la médula de algunas especies de Parmotrema existen diversos compuestos derivados de â-orcinol, depsidonas, dépsidos del orcinol y ácidos grasos.

Caso muy similar ocurre con la especie $R$. americana, de la cual Hale (1979) describe la 
presencia de ácido úsnico y más adelante Brodo (2001) describe la presencia de los ácidos divaricatico, norbarbatico y el 4-0-glomeliferico en la médula. También Barrero y Peréz- Ortega (2003) mencionan que en la médula de esta especie hay presencia de dépsidos, depsidonas y derivados del $\beta$-orcinol.

Stark et al. (2007), extrajeron de especies de Cladonia para pruebas de actividad antibiótica del ácido úsnico y lecanórico, los cuales no fueron identificado en C. ceratophylla. Sin embargo Barrero y PerézOrtega (2003), exponen que los géneros Cladonia y Cladina se tratan conjuntamente, ya que por técnicas de biología molecular no hay muchas diferencias para tratarlos como géneros diferentes. Estos autores realizaron la técnica de TLC y detectaron algunas sustancias que no coincidieron a las descritas en la literatura, aunque no hacen referencia a las mismas.

Los resultados obtenidos en este trabajo se deben quizás, a que muchas de las especies descritas en la literatura consultada son de lugares con condiciones ecológicas y geográficas diferentes a las de Cuba. Estos son factores que pueden hacer variar las características cuantitativas de las sustancias liquénicas en los talos de los líquenes de una misma especie, lo cual se denomina quimiotipos (Culberson, 1986 citado por: Lumbsch, 1998). Para corroborar esta afirmación, teniéndose en cuenta que en cromatografía de capa fina solo se detectan las sustancias de mayor concentración en el talo liquénico, se requieren realizar estudios químicos más profundos (HPLC, Cromatografía gaseosa acoplada a espectrometría de masas) con estas especies cubanas.

\section{CONCLUSIONES}

Los extractos liquénicos más efectivos fueron los obtenidos de Parmotrema praesorediosum para $P$. nicotianae y el de Parmotrema dilatatum para $R$. solani.

Todos los extractos revelaron presencia de metabolitos liquénicos mediante TLC. Se identificaron tres metabolitos liquénicos de los cuales 2 son dépsidos y uno pertenece a la clase de las depsidonas.

\section{AGRADECIMIENTOS}

El Colectivo de autores desea agradecerles a los siguientes investigadores que colaboraron con el desarrollo de este estudio:

Lic. Linda Teresa Guerrero López. Directora de la agencia de viajes Bio-Tour's. Michoacán, México

MsC. Dania Rosabal López. Prof. Universidad de Oriente. Santiago de Cuba, Cuba.

\section{REFERENCIAS}

1.Balaji, P. and Hariharan, G. H. (2007). In vitro antimicrobial activity of Parmotrema praesoredium thallus extracts. Rescarch Journal of Botany. 2 (1): 54-59.

2.Barrero, E. y Pérez- Ortega, S. (2003). Líquenes de la Reserva Natural Integral de Muniellos, Asturias. Serie naturaleza, Cuadernos de medio ambiente. Primera edición. Ediciones. Oviedo. Asturias, España. 522 p.

3.Brodo, I. M.; Duran-Sharnoff S. and Sharnoff, S. (2001). Lichens of North America. Yale University Press, New Haven \& London, UK. 795 p.

4.Gulluce, M.; Aslan, A.; Sokmen, M.; Adiguzel, A.; Agar, G. and Sokmen, A. (2006). Screeing the antioxidant and antimicrobial properties of the lichens
Parmelia saxatilis, Plastismatia glauca, Ramalina pollinaria, Ramalina polymorpha and Umbilicaria nylanderiana. Phytomedicine. (13): 515-521.

5.Hale, M.E. (1979). How to know the lichens. Segunda edición. The pictured key Nature series. Dubuque, lowa. USA. 246 pp.

6.Kusumaningrum I.K.; Suwarso, W.P.; and Cahyana, A.H. (2011). Screening for bioactive compound group in Parmotrema tinctorum's extract and bioactivity Test of dichloromethane extract as anti-tuberculosis againsty Mycobacterium tuberculosis H37RV and toxicity against Artemia salina. Sci. J.UBU. 2 (1): 53 59.

7.Lumbsch, H.T. (1998). The use of metabolic data in 
lichenology at the species and subspecific levels. Lichenologist. 30 (4-5): 357-367.

8.Mietzsch E.; Lumbsch, H.T. and Elix, J.E. (1994): WINTABOLITES (Mactabolites for Windows). - Users manual and computer program, 2nd ed. (Universität Essen) 54p. www.nhc.asu.edu/lherbarium/ lichen info/tlc.php. Última consulta: septiembre 2013.

9.Minter, D.W.; Rodríguez, M. and Mena, J. 2001. Fungi of Caribbean. PDMS Publishing Uk. ISBN: 0954016904, 2001. $1737 \mathrm{pp}$.

10.Nash, I.I.I.; Ryan,T. H.; Diederich, B. D.; Gries, C. and Bungarts, F. (2004). Lichen Flora of the Greater Sonoran Desert Region. Vol II. Lichens Unlimited, Arizona State University. Tempe, Arizona, U.S.A. 742 pp.

11.Nash, I.I.I.; Ryan,T. H.; Diederich, B. D.; Gries, C.; and Bungarts, F. (2007). Lichen Flora of the Greater Sonoran Desert Region, Vol III. Lichens Unlimited, Arizona State University. Tempe, Arizona, U.S.A. 567 pp.

12.Nash, I.I.I.; Ryan,T. H.; Diederich, B. D.; Gries, C. and Bungarts, F. (2001). Lichen Flora of the Greater Sonoran Desert Region, Vol I. Lichens Unlimited, Arizona State University. Tempe, Arizona, U.S.A. 532 pp.

13.0rtega, Ch. M. (2004). Bioactividad del ácido úsnico del complejo de especies de Usnea sp. Biotecipn. 11: 16 pp.

14.Prashith, R. Raghavendra, L.S. Swathi, D. Venugopal, M. and Kanivebagillu, V. (2012). Antifungal and cytotoxic activity of Everniastrum cirrahatum. Chiang Mai J. Sci. 39(1): 76-83.

15.Rankovic, B. and Kosanic, M. (2012). Antimicrobial activities of different extracts of Lecanora atra, Lecanora muralis, Parmelia saxatilis, Parmelia sulcata and Parmeliopsis ambigua. Pak J. Bot. 44 (1): 429-433.
16.Rankovié. B.; Misié, M. and Sukdolak, S. (2009). Antimicrobial activity of extracts of the lichens Cladonia furcata, Parmelia caperata, Parmelia pertusa, Hypogymnia physodes and Umbilicaria polyphylla. Biología. 64(1): 53-58.

17.hahi. S.K.; Shukla, A. C.; Dikshit, A. and Uperti, D.K. (2001). Broad spectrum antifungal properties of the lichen Heterodermia leucomela. The Lichenologist. 33: $177-179$.

18.Soon, O.; Hae, J.; Sook, Kwang, L.; Young, J. and Jae, H. (2006). Antifungal activity of lichen-forming fungi isolated from korean and chinese lichen species against plant pathogenic fungi. Plant Pathol. J. 22(4): 381-385.

19.Suberu, H. (2004). Preliminary studies of inhibitions in Aspergillus flavus with extracts of two lichens and Bentex-T fungicide. African Journal of Biotechnology. 3 (9): 468-472.

20.Thadhani, V.M.; Choudhary, M. I.; Khan, S. and Karunaratne, V. (2012). Antimicrobial and toxicological activities of some depsides and depsidones. J.Natn.Sci.Foundation Sri Lanka. 40(1):43-48.

21.Tiwari, P.; Rai, H.; Upreti, D.K.; Trivedi, S. and Shunkla. P. (2011). Assessment of antifungal activity of some himalayan foliose lichens against plant pathogenic fungi. American Journal of Plant Sciences. 2: 841-846.

22.Toledo, F.J. García, A. León, F. y Bermejo, J. (2004). Ecología química en hongos y líquenes. Rev. Acad. Colomb. Cienc. XXVIII (109): 510-528.

23.Vargas, M. (2000). Programa ED50 plus v1.0. http:/ /www.sciencegateway.org. Última consulta: noviembre 2012.

24.Wei, X.; Hae-Sook, J.; Keon, H.; Young, K. and Jae-Seoun, H. (2008). Antifungal activity of lichenforming fungi against Colletotrichum acutatum on hot pepper. Plant Pathol. J. 24 (2): 202-206. 